\section{Chemical Societies}

SIR,-Your recent editorial about the Society of Chemical Industry (SCI) has just been brought to my notice (Nature, 231, 411; 1971) and, as I believe I was the only individual member to protest against the proposed merger of the SCI with the other chemical bodies, may I explain why I did so? Other protests came from members of one of the sections of the SCI (Chemistry and Industry, 1592, December 12, 1970).

I am a member of the Chemical Society (CS) and SCI, but not of the Royal Institute of Chemistry (RIC) because I do not satisfy the professional membership requirements.

The original proposals were for the amalgamation of the three bodies under a new unifying charter and, as long as this was the case, I was in favour and voted accordingly in the CS referendum. As long as a new charter was the ultimate aim, any divergence on the way towards it was not important, for it seemed certain that the lawyers advising the Privy Council would sort out anything which ought not to be allowed. Suddenly, however, in a document issued to members by the CS, what was to be the new CS became the "new" CS and it appeared obvious that amalgamation under a new charter was not contemplated within the foreseeable future. As none of the bodies have power in their charters to amalgamate, any other kind of amalgamation was, therefore, unlawful.

As far as the CS is concerned, I am now waiting to see the scheme which the Charity Commissioners must be drafting for the uniting of two charitable bodies (CS and the Faraday Society) with two which are not (RIC and the Society for Analytical Chemistry). Because there is no power to amalgamate in the charter of the CS, this scheme will show how it can all be done through new bye-laws alone, which themselves may be inconsistent with the charter (Council Members "appointed by" the RIC against "electing . . . other Members of Council" by the Fellows; Fellows of "any nationality" against "loving subjects"). It will also show how these new bye-laws are to be approved at a meeting which, somehow, took place on April 21,1971 , when a resolution was passed for the new bye-laws to come into force forthwith. It will then reconcile that with the supplementary charter which says that "no such resolution ... shall become effective .... until the expiration of one month" and will then reconcile the whole with the original charter, which declares "no resolution or Bye-law shall on any account . . . be made . . . in opposition to the general scope, true intent and meaning" of the charter or of the laws or statutes of the realm (including the Charities Act, 1960?) and that if any such "rule or Bye-law shall be made, the same shall be absolutely null and void to all intents, effects, constructions, and purposes whatsoever".

How, in 1971, can the powers of the CS be so wide under its charter that it can amalgamate with (to be taken over by?) the RIC, when, in 1876, the "limited powers of the Chemical Society under its charter" were such that it could not accommodate within its own corporate identity that body of professional chemists which eventually became the RIC? (See The Chemical Society 1841-1941, pp. 52 and 53.) In any explanation, I hope account will be taken of the fact that the only thing which seems to have changed since 1876 is the addition of a supplementary charter in 1920 and that took away the class of associateship under which professional chemists might possibly have been accommodated.

In your editorial of November 14, 1970 (Nature, 228, 597; 1970), you mention the "enormous expense of renegotiating a single" charter. Could not some of this expense have been avoided (anyway, for those bodies which are charities-the CS and SCI) by asking the Charity Commissioners to prepare a scheme under section 15 of the Charities Act? This provides machinery for amending, free of charge to the charity, the charters of those charities which are established by Royal Charter. The idea is partly to stop charities needlessly incurring legal costs when the Commissioners can do what is necessary without charge to the charity. Charity money should be spent on charitable objects and anything the commissioners do for free means that just so much more will be so spent.

Yours faithfully,

J. C. WILliams

60A High Street,

Edgware

Middlesex $H A 87 E J$

\section{Smoking and Cancer}

SIR,--It would be a pity if the somewhat personal nature of the exchanges between Dr John Higginson (Nature, 232, 355; 1971) and Dr T. D. Sterling (Nature, 231, $543 ; 1971)$, about the availability of unpublished data on smoking and lung cancer, were to obscure a real point of principle involved.

A scientific author basing his conclusions on the results of an experiment takes it for granted that he has to publish enough information for the experiment to be repeated, and its results confirmed or not, as the case may be. In biology and medicine, and in the social sciences, conclusions may sometimes be drawn from observations which cannot be repeated, but here also the data ought to be made publicly available, to allow other interpretations. No useful scientific purpose is served by publishing unverifiable hypotheses; and that is so even if they are unverifiable only because the information needed for verification is kept private.

Ideally everything relevant ought to be published, but for reasons of space that may be impossible. As Dr Sterling has pointed out, this has not been done with most of the smoking/lung cancer investigations, and perhaps in other medical fields as well, where published conclusions have been derived from data which are not generally available, except by favour of the authors. This is unsatisfactory, since it is in no way to "impugn the integrity and competence of the numerous scientists and committees in many countries who have reviewed exhaustively the extensive data published "on this subject" (if I may quote Dr Higginson) to accept that there is at least a remote chance that some of them may have been mistaken, and that there might be advantages in allowing a fresh look from an unprejudiced, or at any rate a different, point of view.

Granted that much of the data may be in a form unsuitable for publication in scientific journals, and that it would clearly be quite wrong to conclude that a busy and important medical scientist "who fails to make his data available to any Tom, Dick or Harry is lacking in credibility" (to quote Dr Higginson again), would it not be possible to have an arrangement whereby the data are deposited in some central library or institute and publicly available without reference to the author, to be copied and quoted from just as though they had been published with the original paper?

The British Museum (Natural History) has for many years operated such a scheme for biological and ecological data, which are often both voluminous and undigestible, and which journal editors are rightly reluctant to print, substituting instead a note to indicate where they are to be found in full. This seems to work well enough, and allows an author to refer to unprinted results without any fear of being accused of keeping them to himself, away from public investigation and criticism.

$$
\text { Yours faithfully, }
$$

$$
\text { C. B. GoOdhaRT }
$$

University Museum

of Zoology, Cambridge 